\title{
Suppression of human breast cancer cells by tectorigenin through downregulation of matrix metalloproteinases and MAPK signaling in vitro
}

\author{
LINWEN ZENG ${ }^{*}$, SHAOFENG YUAN* , JIANLIANG SHEN, MING WU, \\ LIANGMING PAN and XIANGDONG KONG
}

Department of Surgery, Tinglin Hospital of Jinshan District, Shanghai 201505, P.R. China

Received March 29, 2017; Accepted November 9, 2017

DOI: $10.3892 / \mathrm{mmr} .2017 .8313$

\begin{abstract}
Breast cancer is a major life-threatening malignancy and is the second highest cause of mortality. The aim of the present study was to investigate the effects of tectorigenin (Tec), a Traditional Chinese Medicine, against human breast cancer cells in vitro. MDA-MB-231 and MCF-7 human breast cancer cells were treated with various concentrations of Tec. Cell proliferation was evaluated using the Cell Counting kit-8 assay, and apoptosis and the cell cycle were examined by flow cytometry. The migratory and invasive abilities of these cells were detected by Transwell and Matrigel assays, respectively. Metastasis-, apoptosis- and survival-related gene expression levels were measured by reverse transcription-quantitative polymerase chain reaction and western blotting. The results indicated that Tec was able to inhibit the proliferation of MDA-MB-231 and MCF-7 cells in a dose- and time-dependent manner. Furthermore, Tec treatment induced apoptosis and G0/G1-phase arrest, and inhibited cell migration and invasion. Tec treatment decreased the expression of matrix metalloproteinase (MMP)-2, MMP9, BCL-2, phosphorylated-AKT and components of the mitogen-activated protein kinase (MAPK) signaling pathway, and increased the expression of BCL-2-associated X, cleaved poly [ADP-ribose] polymerase and cleaved caspase-3. In conclusion, Tec treatment suppressed human breast cancer cells through the downregulation of AKT and MAPK signaling and the upregulated expression and/or activity of the caspase family in vitro. Therefore, Tec may be a potential therapeutic drug to treat human breast cancer.
\end{abstract}

Correspondence to: Dr Xiangdong Kong or Dr Liangming Pan, Department of Surgery, Tinglin Hospital of Jinshan District, 80 North Siping Road, Tinglin Town, Jinshan, Shanghai 201505, P.R. China

E-mail: medxdkong@163.com

E-mail: docliangmingpan@163.com

*Contributed equally

Key words: tectorigenin, breast cancer, anticancer agent, apoptosis, caspase family

\section{Introduction}

Breast cancer is a major life-threatening malignancy and ranks as the second leading cause of mortality $(1,2)$. Triple-negative (TN) breast cancer accounts for $\sim 15 \%$ of all diagnosed breast cancers. TN breast cancer cells do not express estrogen receptor, progesterone receptor or human epidermal growth factor receptor $(3,4)$. Drug-resistant TN breast cancers have a poor prognosis, as they metastasize rapidly and are difficult to treat (5). MDA-MB-231 TN breast cancer cells are aggressive, invasive and resistant to a number of anticancer agents (6). On this basis, MDA-MB-231 cells provide an ideal in vitro model in which to analyze the effects of anticancer treatments, such as with tectorigenin (Tec). MCF-7 cells are an estrogen-responsive breast cancer cell line, which was used to confirm the inhibitory effects of Tec on cell proliferation, migration and invasion. Chemotherapeutic drugs that inhibit the malignant characteristics of MDA-MB-231 and MCF-7 cells would be the best drugs to treat breast cancer.

Experience-based remedies such as Traditional Chinese Medicines (TCMs) have been derived over many years of clinical use in China. Most TCMs are extracted from at least one medicinal herb and comprise multiple bioactive ingredients, which suggested that TCMs may be a potential source for new anticancer drugs (7). To date, a number of naturally occurring phytochemicals have been reported that exhibit antitumoral effects by inducing apoptosis and have received considerable attention $(1,2,4)$. Tec is an effective component of the TCM that is derived from Belamcanda chinensis (8). Tec has been reported to exhibit beneficial effects in various types of tumors, including osteosarcoma (9), ovarian cancer (10), lung carcinoma (11), hepatocellular carcinoma (12) and promyelocytic leukemia (13). In addition, Tec was revealed to regulate adipogenic differentiation and adipocytokine secretion through peroxisome proliferator-activated receptor- $\gamma$ and $\mathrm{I} \kappa \mathrm{B}$ kinase/nuclear factor- $\kappa \mathrm{B}$ signaling (14). In addition, previous studies also reported that Tec affects the proliferation of breast cancer cells $(15,16)$. However, the specific effects and the underlying mechanisms of Tec on apoptosis and metastasis in human breast cancer have not been elucidated.

Based on the present study results, it is hypothesized that Tec may induce apoptosis in breast cancer cells by downregulating 
the protein expression of matrix metalloproteinases (MMPs), phosphorylated (p)-AKT and mitogen-activated protein kinase (MAPK) signaling and by upregulating the expression of cleaved caspase (CASP)-3 and cleaved poly [ADP-ribose] polymerase (PARP) as MMPs, p-AKT, MAPK signaling, cleaved CASP-3 and cleaved PARP have been linked to the apoptosis or metastasis of breast cancer in previous reports $(3,4,9,10)$. Therefore, Tec may be a potential therapeutic drug for human breast cancer.

\section{Materials and methods}

Main reagents. Tec was purchased from Sigma-Aldrich (Merck KGaA, Darmstadt, Germany) and was dissolved in DMSO at a concentration of $200 \mathrm{mM}$ and stored at $-20^{\circ} \mathrm{C}$. Primary antibodies against MMP2 (cat. no. 87809), MMP9 (cat. no. 13667), BCL-2 (cat. no. 4223), BCL-2-associated X (BAX; cat. no. 5023), p-AKT (cat. no. 4060), total-AKT (cat. no. 4685), p-c-Jun N-terminal kinase (JNK; cat. no. 4668), total-JNK (cat. no. 9252), p-p38 (cat. no. 4511), p38 (cat. no. 8690), p-extracellular signal-regulated kinase (ERK; cat. no. 4370), total-ERK (cat. no. 4695), cleaved CASP-3 (cat. no. 1050), CASP-3 (cat. no. 14220), cleaved PARP (cat. no. 5625), PARP (cat. no. 9532) and GAPDH (cat. no. 2118) and anti-rabbit IgG $(\mathrm{H}+\mathrm{L})$ secondary antibody (DyLight ${ }^{\mathrm{TM}}$ 800 4X PEG conjugate; cat. no. 5151) were purchased from Cell Signaling Technology, Inc. (Danvers, MA, USA).

Cell lines and cell culture. Human breast cancer cell lines MDA-MB-231 and MCF-7, and the human mesenchymal stem cell (hMSC) lines were purchased from the Chinese Academy of Sciences (Shanghai, China) the repository of ATCC cell lines in China. MDA-MB-231 and MCF-7 cell lines were cultured in Dulbecco's modified Eagle's medium (DMEM; Gibco; Thermo Fisher Scientific, Inc., Waltham, MA, USA) supplemented with $10 \%$ fetal bovine serum (FBS; Gibco; Thermo Fisher Scientific, Inc.) and $1 \%$ penicillin-streptomycin solution (Gibco; Thermo Fisher Scientific, Inc.), and containing $<0.05 \%$ DMSO, at $37^{\circ} \mathrm{C}$ in a humidified atmosphere with $5 \% \mathrm{CO}_{2}$. hMSCs were cultured in $\alpha$-minimum essential medium ( $\alpha$-MEM; Gibco; Thermo Fisher Scientific, Inc.) supplemented with 10\% FBS and $1 \%$ penicillin-streptomycin solution at $37^{\circ} \mathrm{C}$ in a humidified atmosphere with 5\% CO 2 . MDA-MB-231 and MCF-7 cells were used within 20 passages, and hMSCs were used within 5 passages.

Measurement of cell viability. Cell viability was measured using the Cell Counting kit-8 (CCK-8), as previously described (17). Briefly, MDA-MB-231 and MCF-7 cells (6,000 cells/well) were plated in a 96 -well plate and incubated overnight at $37^{\circ} \mathrm{C}$ without drug treatment. Subsequently, the cells of the control group ( $0 \mu \mathrm{M}$ group) were treated with $0.1 \%$ DMSO and the cells in the Tec groups were treated with Tec at concentrations of $0,50,100$ or $200 \mu \mathrm{M}$ and incubated at $37^{\circ} \mathrm{C}$. The present study used 0-200 $\mu \mathrm{M}$ Tec as the experimental dose according to a pretest study and previously published studies $(9,10)$. Viability was examined every $24 \mathrm{~h}$ following treatment (that is, at $24,48,72$ and $96 \mathrm{~h}$ ) by incubating the cells with CCK- 8 solution at $37^{\circ} \mathrm{C}$ for $2 \mathrm{~h}$ and measuring optical density (OD) at $490 \mathrm{~nm}$ using a microplate reader (Thermo Electron
Corporation; Thermo Fisher Scientific, Inc.). Each condition included three replicate wells with at least three independent repeats. Cell viability compared to the control was calculated using the following equation: Cell viability $(\%)=\mathrm{OD}_{\text {drug-treated }}$ group $/ \mathrm{OD}_{\text {control group }}$ The cell viability of hMSCs was detected using the above methods at 72 and $96 \mathrm{~h}$ following Tec treatment. If there were no effect on the cell viability of hMSCs at 72 and 96 h, 24 and 48 h should also demonstrate no effect. As a result, the inhibition of proliferation in MCF-7 was more obvious than in MDA-MB-231 cells, so these were selected to detect the apoptosis, cell cycle and apoptosis-related genes of MDA-MB-231 cells in subsequent experiments.

Apoptosis. Apoptosis was measured by flow cytometry using Annexin V-fluorescein isothiocyanate (FITC)/propidium iodide (PI) double-immunofluorescence staining kit (Thermo Fisher Scientific, Inc.), according to the manufacturer's protocol. Briefly, MDA-MB-231 cells $\left(1 \times 10^{6}\right.$ cells/well) were seeded in 6-well plates and harvested $24 \mathrm{~h}$ following treatment with 0,100 or $200 \mu \mathrm{M}$ Tec. As $50 \mu \mathrm{M}$ was far less than $\mathrm{IC}_{50}$ at $24 \mathrm{~h}$ in MDA-MB-231 cells, this concentration was removed. The cells were vigorously pipetted and centrifuged at $500 \mathrm{x} \mathrm{g}$ for $5 \mathrm{~min}$ at $4^{\circ} \mathrm{C}$ and the supernatants were discarded. Subsequently, the cells were resuspended in $1 \mathrm{X}$ Annexin-binding buffer to verify drug-induced apoptosis rates, and apoptotic events were indicated as a combination of $\mathrm{FITC}^{+} / \mathrm{PI}^{-}$(early apoptotic) and $\mathrm{FITC}^{+} / \mathrm{PI}^{+}$(late apoptotic or dead), and were analyzed using FlowJo version 7.6 (FlowJo LLC, Ashland, OR, USA). The final results are expressed as the percentage of $\mathrm{FITC}^{+}$cells after subtracting the number of vehicle cells. Data are presented as the mean \pm standard deviation from at least three independent experiments.

Cell cycle analysis. To analyze the effects of Tec on cell cycle, MDA-MB-231 cells ( $2 \times 10^{6}$ cells/dish) were seeded in $60 \mathrm{~mm}$ culture dishes and treated with 0,100 or $200 \mu \mathrm{M}$ Tec for $24 \mathrm{~h}$ at $37^{\circ} \mathrm{C}$. Cells were harvested, washed twice with PBS and fixed in $70 \%$ ice-cold ethanol at $-20^{\circ} \mathrm{C}$ for $2 \mathrm{~h}$, followed by 2 washes with PBS. Cells were resuspended in $300 \mu 1$ PI/RNase staining buffer (BD Biosciences, Franklin Lakes, NJ, USA) for $10 \mathrm{~min}$ at room temperature and analyzed using a BD FACSCalibur flow cytometer (BD Biosciences). The cell cycle distribution was analyzed with the ModFit LT software version 3.0 (BD Biosciences). Data are presented as the mean \pm standard deviation from at least three independent experiments.

Tumor cell migration and invasion ability. Cell migration was analyzed using a Transwell assay with $8 \mu \mathrm{m}$ cell culture inserts (EMD Millipore, Billerica, MA, USA) in 24-well plates. Untreated and Tec-treated MDA-MB-231 and MCF-7 cells $\left(3 \times 10^{4}\right.$ cells/well) were suspended in $100 \mu$ of serum-free DMEM and added to the upper Transwell chamber, whereas the lower chamber was filled with $500 \mu 1$ complete DMEM with $20 \% \mathrm{FBS}$. Following incubation for $24 \mathrm{~h}$ at $37^{\circ} \mathrm{C}$ in a $5 \% \mathrm{CO}_{2}$ atmosphere, the insert was washed with PBS and cells on the top surface of the insert were removed by wiping with a cotton swab. Cells that migrated to the bottom surface of the insert were fixed with $4 \%$ paraformaldehyde at room temperature for $20 \mathrm{~min}$, stained with $0.1 \%$ crystal violet at 
room temperature for $20 \mathrm{~min}$, and examined using a light microscope (BX43; Olympus Corporation, Tokyo, Japan). Cell counts were based on examination of five random fields from the digital images (magnification, x200) and reported as the mean \pm standard deviation. All assays were repeated three times independently.

The invasion assay procedure was similar to that of the cell migration assay, except that the Transwell membrane was coated with 1:3 diluted Matrigel (BD Biosciences), and the cells were incubated for $32 \mathrm{~h}$ at $37^{\circ} \mathrm{C}$. All assays were repeated three times independently.

Reverse transcription-quantitative polymerase chain reaction $(R T-q P C R)$. A total of $24 \mathrm{~h}$ post-treatment with different doses of Tec, RNA was extracted from MDA-MB-231 cells $\left(1 \times 10^{6}\right.$ cells/well) using the TRIzol (Invitrogen; Thermo Fisher Scientific, Inc.) method and RNA extracted according to the manufacturer's protocol. The concentration and purity were measured by Nanodrop 2000 system (Thermo Fisher Scientific, Inc., Wilmington, DE, USA). The iScript cDNA Synthesis kit (Bio-Rad Laboratories, Inc., Hercules, CA, USA) was used to synthesize cDNA using the reverse transcription method according to the manufacturer's protocol. mRNA expression levels were evaluated by qPCR using a SYBR Premix ex Taq, Tli RNase H Plus kit (Takara Bio, Inc., Otsu, Japan) according to the manufacturer's protocol. The thermocycling conditions were as follows: 40 cycles of $95^{\circ} \mathrm{C}$ for $5 \mathrm{sec}$ and $60^{\circ} \mathrm{C}$ for $34 \mathrm{sec}$. Primer sequences are listed in Table I. GAPDH was used as an internal control and for normalization of expression. Data are presented as the mean \pm standard deviation from at least three independent experiments. Gene expression was compared using the $2^{-\Delta \Delta \mathrm{Cq}}$ method (18).

Western blot analysis. Protein extracts from MDA-MB-231 cells $\left(1 \times 10^{6}\right.$ cells/well) subjected to various Tec treatments were prepared using $120 \mu \mathrm{l}$ radioimmunoprecipitation assay lysis buffer (RIPA; Thermo Fisher Scientific, Inc.) supplemented with $1 \mathrm{mM}$ phenylmethylsulfonyl fluoride and were quantified using a Bicinchoninic Acid Protein Assay kit (Thermo Fisher Scientific, Inc.). Lysates were diluted 5:1 with loading buffer and heat-denatured at $99^{\circ} \mathrm{C}$ for $10 \mathrm{~min}$. Equal amounts of protein $(30 \mu \mathrm{g})$ were resolved by SDS-PAGE using precast $7.5-12.5 \%$ gels (Thermo Fisher Scientific, Inc., USA) at $80 \mathrm{~V}$ for $30 \mathrm{~min}$ and $120 \mathrm{~V}$ for $1 \mathrm{~h}$. Proteins were transferred onto an activated polyvinylidene fluoride membrane by wet electrophoretic transfer (Bio-Rad Laboratories, Inc.) for $2.5 \mathrm{~h}$ at a constant current of $250 \mathrm{~mA}$. The membranes were blocked for $1 \mathrm{~h}$ in TBS containing $0.05 \%$ Tween-20 (TBST) and $5 \%$ nonfat milk powder and subsequently incubated overnight with primary antibodies (all antibodies at 1:1,000) at $4^{\circ} \mathrm{C}$. Following three washes in TBST, the membranes were probed with the corresponding secondary antibody $(1: 15,000)$ for $1 \mathrm{~h}$ at room temperature. The membranes were washed in TBS, and the protein bands were visualized using an Odyssey Infrared Imaging System (LI-COR Biosciences, Lincoln, NE, USA). Positive immunoreactive bands were densitometrically quantified and normalized to GAPDH. Adobe Photoshop (Creative Suite 5; Adobe Systems, Inc., San Jose, CA, USA) was used for densitometry. Data are presented as
Table I. Primer sequences used in reverse transcriptionquantitative polymerase chain reaction.

\begin{tabular}{|c|c|}
\hline Gene & Primer sequence $\left(5^{\prime} \rightarrow 3^{\prime}\right)$ \\
\hline MMP2 & $\begin{array}{l}\text { F: ATGCAGTGGGGGCTTAAGAA } \\
\text { R: AAACAGGTTGCAGCTCTCCT }\end{array}$ \\
\hline MMP9 & $\begin{array}{l}\text { F: TCTATGGTCCTCGCCCTGAA } \\
\text { R: CATCGTCCACCGGACTCAAA }\end{array}$ \\
\hline AKT1 & $\begin{array}{l}\text { F: GAAGGACGGGAGCAGGC } \\
\text { R: CTCACGCGCTCCTCTCAG }\end{array}$ \\
\hline AKT2 & $\begin{array}{l}\text { F: GCCACCATGAATGAGGTGAAT } \\
\text { R: TCTCGTCTGGAGAATCCACG }\end{array}$ \\
\hline AKT3 & $\begin{array}{l}\text { F:TTTTCTCTATTATTTGGGCTGAGTC } \\
\text { R: CСССТСТTCTGAACCCAACC }\end{array}$ \\
\hline BCL-2 & $\begin{array}{l}\text { F: ATCTGGGCCACAAGTGAAGT } \\
\text { R: GCTGATTCGACGTTTTGCCT }\end{array}$ \\
\hline BAX & $\begin{array}{l}\text { F: AGAGGTCTTTTTCCGAGTGGC } \\
\text { R: CAGGGACATCAGTCGCTTCAG }\end{array}$ \\
\hline CASP-3 & $\begin{array}{l}\text { F: GCTCTGGTTTTCGGTGGGTG } \\
\text { R: CTGAGGTTTGCTGCATCGAC }\end{array}$ \\
\hline CASP-8 & $\begin{array}{l}\text { F: CTGGTCTGAAGGCTGGTTGT } \\
\text { R: CAGGCTCAGGAACTTGAGGG }\end{array}$ \\
\hline CASP-9 & $\begin{array}{l}\text { F: CAGGCTCAGGAACTTGAGGG } \\
\text { R: TCGACAACTTTGCTGCTTGC }\end{array}$ \\
\hline GAPDH & $\begin{array}{l}\text { F: AATGGGCAGCCGTTAGGAAA } \\
\text { R: GCGCCCAATACGACCAAATC }\end{array}$ \\
\hline
\end{tabular}

BAX, BCL-2-associated X; CASP, caspase; F, forward; MMP, matrix metalloproteinase; $\mathrm{R}$, reverse.

Table II. $\mathrm{IC}_{50}$ calculated for varying incubation periods for tectorigenin treatment on two breast cancer cell lines.

\begin{tabular}{lcccc}
\hline & \multicolumn{4}{c}{$\mathrm{IC}_{50}(\mu \mathrm{M})$} \\
\cline { 2 - 5 } Cell line & $24 \mathrm{~h}$ & $48 \mathrm{~h}$ & $72 \mathrm{~h}$ & $96 \mathrm{~h}$ \\
\hline MDA-MB-231 & 417.4 & 283.9 & 184.2 & 77.4 \\
MCF-7 & 276.8 & 118.4 & 55.36 & 23.65 \\
\hline
\end{tabular}

$\mathrm{IC}_{50}$, inhibitory concentration $50 \%$.

the mean \pm standard deviation from at least three independent experiments.

Statistical analysis. The Statistical Package for the Social Sciences (SPSS) version 19.0 (IBM Corp., Armonk, NY, USA) was used to analyze the data. Significant differences between experimental groups and controls were assessed using the Student's t-test or one-way analysis of variance and LSD test as appropriate. The data are expressed as the mean \pm standard deviation. $\mathrm{P}<0.05$ was considered to indicate a statistically significant difference. 
A<smiles>COc1c(O)cc2occ(-c3ccc(O)cc3)c(=O)c2c1O</smiles>

B

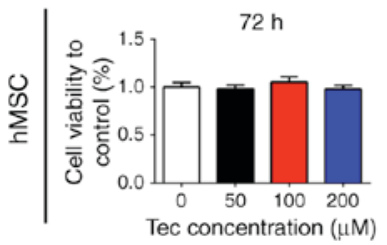

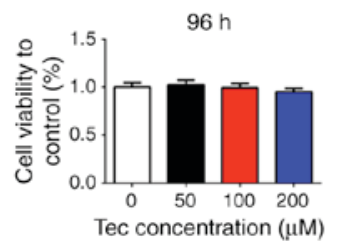
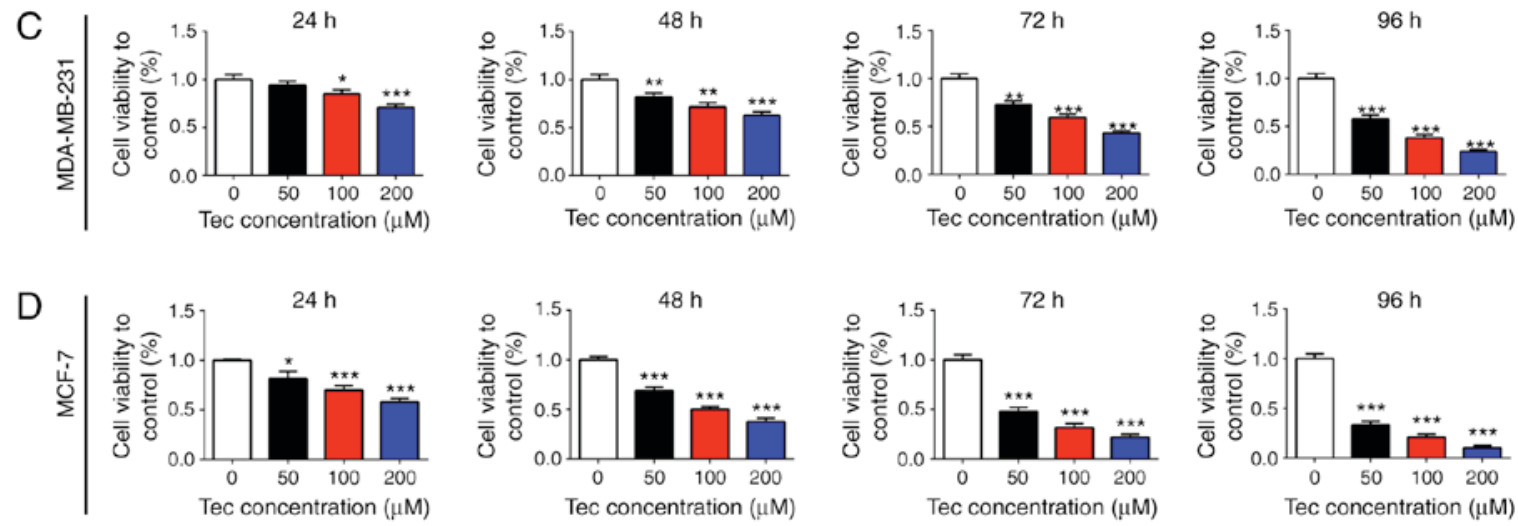

Figure 1. Tec treatment inhibits proliferation of breast cancer cells. (A) Chemical structure of Tec. (B) Tec exhibited no effects on hMSC proliferatin following 72 or 96 h treatment. Tec inhibited the proliferation of (C) MDA-MB-231 and (D) MCF-7 cells in a dose- and time-dependent manner. Data are presented as the mean \pm standard deviation from at least three independent experiments; ${ }^{*} \mathrm{P}<0.05,{ }^{* *} \mathrm{P}<0.01$ and ${ }^{* * *} \mathrm{P}<0.001$ vs. DMSO treated-control $(0 \mu \mathrm{M})$. hMSC, human mesenchymal stem cell; Tec, tectorigenin.

\section{Results}

Proliferation of breast cancer cells and hMSCs following Tec treatment. The structure of Tec is provided in Fig. 1A; molecular weight, 300.26. To investigate the effects of Tec treatment on breast cancer cells, a CCK-8 cell proliferation assay was performed on MDA-MB-231 and MCF-7 cells; no significant differences were identified in hMSCs following 72 or $96 \mathrm{~h}$ Tec treatment (Fig. 1B). The proliferation of MDA-MB-231 and MCF-7 cells was inhibited following treatment with Tec, and the inhibitory effects of Tec on proliferation significantly increased with the increasing Tec concentration in both cell lines, with the strongest effects observed following $96 \mathrm{~h}$ treatment (Fig. 1C and D, respectively). The $50 \%$ inhibitory concentration $\left(\mathrm{IC}_{50}\right)$ was calculated (Table II). According to previous studies $(9,10)$ as well as the present $\mathrm{IC}_{50}$ results, it was determined that the concentrations of Tec at $0,50,100$ and $200 \mu \mathrm{M}$ were to be used in subsequent experiments. These results indicated that Tec treatment inhibited the proliferation of breast cancer cells in a dose- and time-dependent manner.

Tec-induced apoptosis and cell cycle arrest of MDA-MB-231 cells. Flow cytometry was used to detect Tec-induced apoptosis. Treatments with 100 and $200 \mu \mathrm{M}$ Tec significantly increased the total apoptotic rates (18.5 and $29.97 \%$, respectively) compared with the apoptotic rate in untreated control cells $(3.28 \%$; $\mathrm{P}<0.05$; Fig. $2 \mathrm{~A}$ and $\mathrm{B}$ ); quantitative data for early and late apoptosis rate were consistent with this phenomenon (Fig. 2B). The cell cycle was also examined by flow cytometry following PI staining. Tec treatments significantly increased the proportion of G0/G1-phase cells and significantly decreased the proportion of S-phase and G2/M cells (Fig. 2C and D), which suggested that Tec treatment may induce G0/G1-phase arrest in MDA-MB-231 cells. These results indicated that the inhibitory function of Tec may be through activating the apoptosis pathway and G0/G1-phase arrest in MDA-MB-231 cells.

Tec treatment impairs migration and invasion of breast cancer cells and inhibits the expression of metastasis-related genes. Cell migration and invasion were examined using Transwell and Matrigel assays, respectively, following treatment with different concentrations of Tec. The results revealed that the migratory and invasive abilities of MDA-MB-231 and MCF-7 cells were inhibited by Tec in a dose-dependent manner (Fig. 3A and $\mathrm{B}$, respectively). In addition, the mRNA expression levels of MMP2 and MMP9 were inhibited by Tec treatment in a dose-dependent manner in both MDA-MB-231 and MCF-7 cells (Fig. 3C). As the metastasis ability of MDA-MB-231 is stronger than MCF-7 cells $(1,4)$, western blotting analysis was not performed for MMP expressions in MCF-7 cells. The inhibitory effects of Tec on the protein expression of MMP2 and MMP9 in MDA-MB-231 cells were confirmed (Fig. 3D). These results indicated that Tec may impair migration and invasion of breast cancer by suppressing MMP2 and MMP9 expression.

Apoptosis- and survival-related gene expression. To investigate the molecular mechanisms of the inhibitory effects of Tec in MDA-MB-231 cells, RT-qPCR was used to examine the variation in apoptosis- and survival-related gene expression levels. The mRNA expression levels of BCL-2, AKT1, AKT2 and AKT3 were reduced in Tec-treated MDA-MB-231 cells in a dose-dependent manner (Fig. 4A-D, respectively), whereas the expression levels of BAX, CASP-3, CASP-8 and CASP-9 were upregulated (Fig. 4E-H, respectively). These results suggested that these genes may be potential downstream targets of Tec in breast cancer treatment. 
A $\operatorname{Tec}(\mu \mathrm{M})$

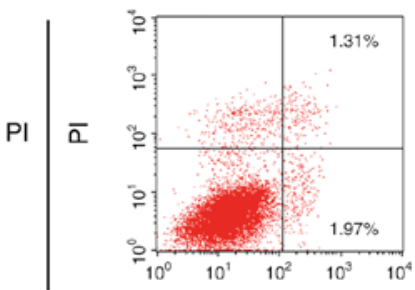

100

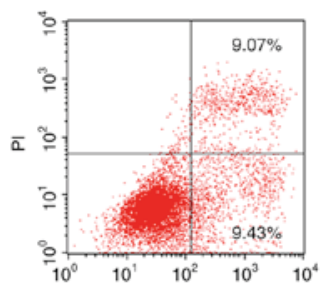

Annexin $\mathrm{V}$
200

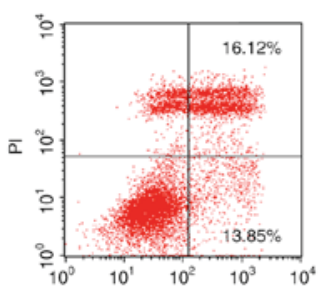

\begin{tabular}{lllll}
$10^{0}$ & $10^{1}$ & $10^{2}$ & $10^{3}$ & $10^{4}$ \\
\hline
\end{tabular}

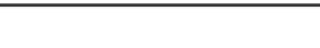

B

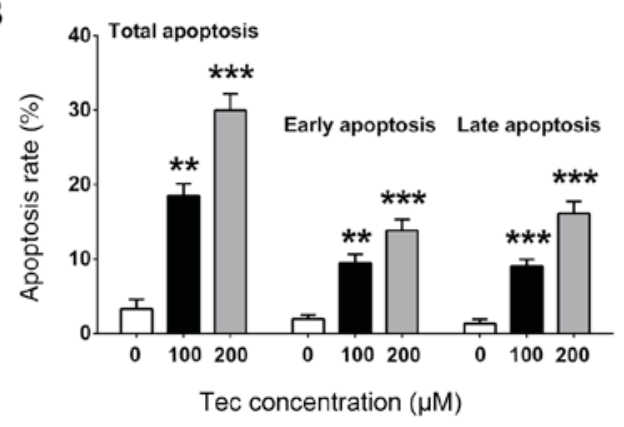

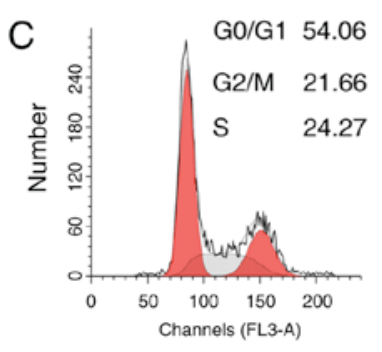

$\operatorname{Tec}(\mu \mathrm{m}) \quad 0$

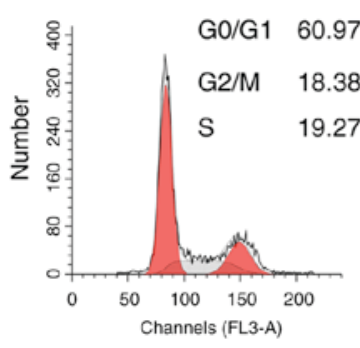

100

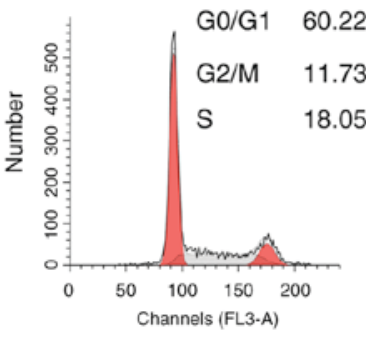

200

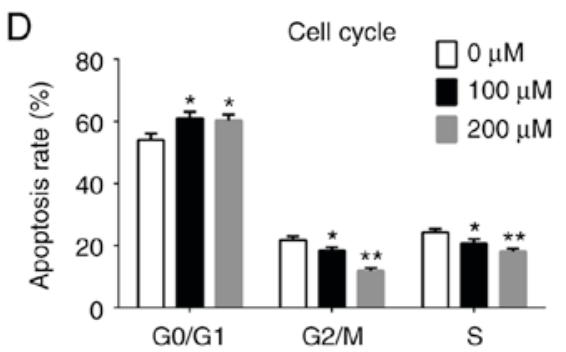

Figure 2. Apoptosis and cell cycle arrest of MDA-MB-231 breast cancer cells following Tec treatment. (A) Flow cytometry-based assessment of apoptosis in MDA-MB-231 cells treated with varying concentrations of Tec for $24 \mathrm{~h}$. (B) Total, early and late apoptosis rates of MDA-MB-231 cells from (A). Apoptotic events are indicated as a combination of FITC+/PI- (early apoptotic) and FITC+/PI+ (late apoptotic or dead) (C) MDA-MB-231 cells were treated with Tec for $24 \mathrm{~h}$, and the relative number of cells in each cell cycle phase was analyzed by flow cytometry. (D) Cell cycle distribution in MDA-MB-231 cells from part (B). Data are presented as the mean \pm standard deviation from at least three independent experiments; $\mathrm{P}<0.05,{ }^{* *} \mathrm{P}<0.01$ and ${ }^{* * * *} \mathrm{P}<0.001$ vs. DMSO treated control $(0 \mu \mathrm{M})$. PI, propidium iodide; Tec, tectorigenin.
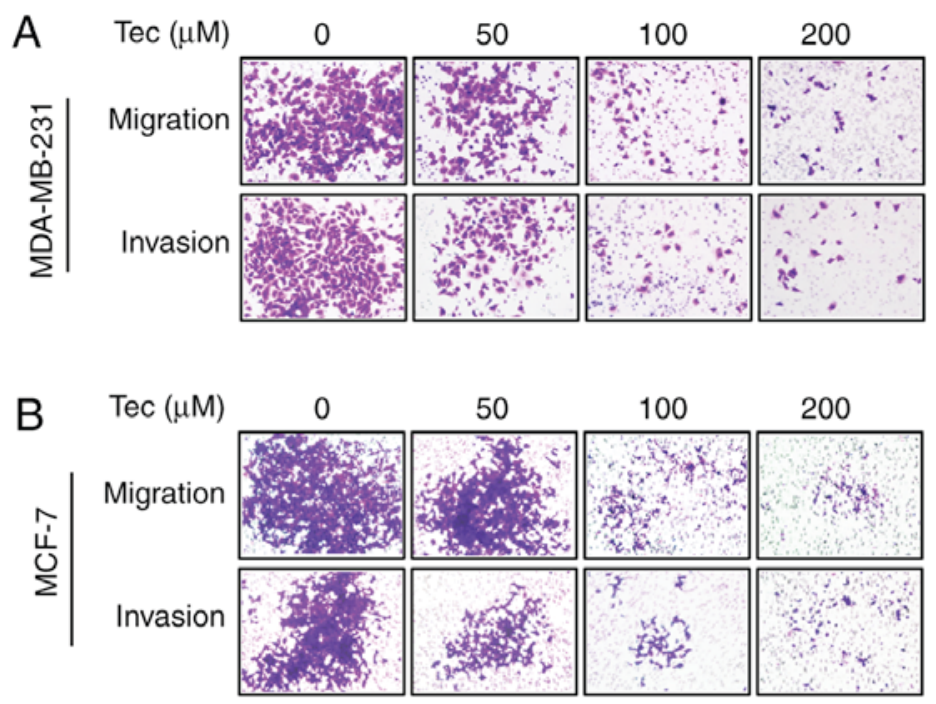

C

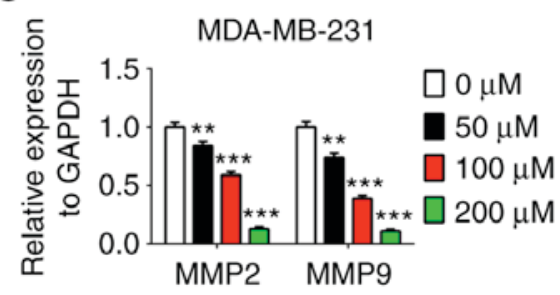

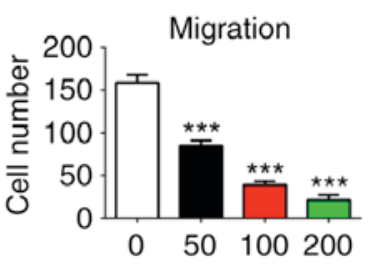

Tec concentration $(\mu \mathrm{M})$

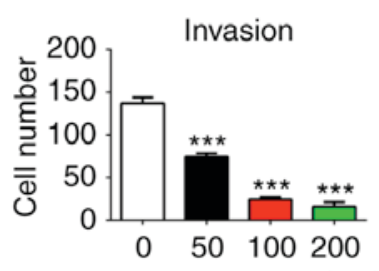

Tec concentration $(\mu \mathrm{M})$

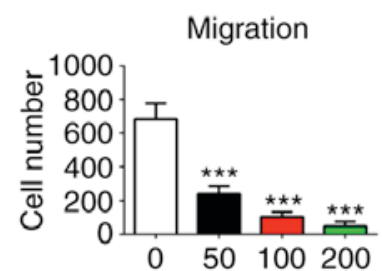

Tec concentration $(\mu \mathrm{M})$

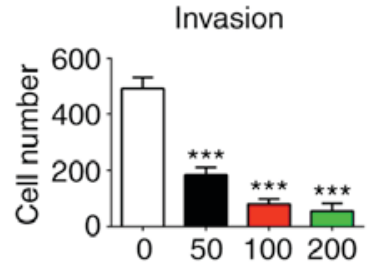

Tec concentration $(\mu \mathrm{M})$

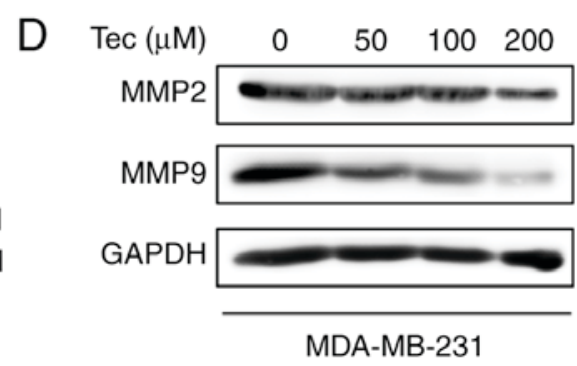

Figure 3. Migration and invasion of breast cancer cells and metastasis-related gene expression following Tec treatment. (A and B). Transwell and Matrigel assays were used to determine the migration and invasion, respectively, of (A) MDA-MB-231 and (B) MCF-7 cells following Tec treatment. (C) MMP2 and MMP9 mRNA expression in MDA-MB-231 and MCF-7 cells following Tec treatments. (D) Western blotting detected the protein expression levels of MMP2 and MMP9 in MDA-MB-231 cells following Tec treatment. Data are presented as the mean \pm standard deviation from at least three independent experiments; ${ }^{* *} \mathrm{P}<0.01$ and ${ }^{* * * *} \mathrm{P}<0.001$ vs. DMSO treated control $(0 \mu \mathrm{M})$. MMP, matrix metalloproteinase; Tec, tectorigenin. 
A

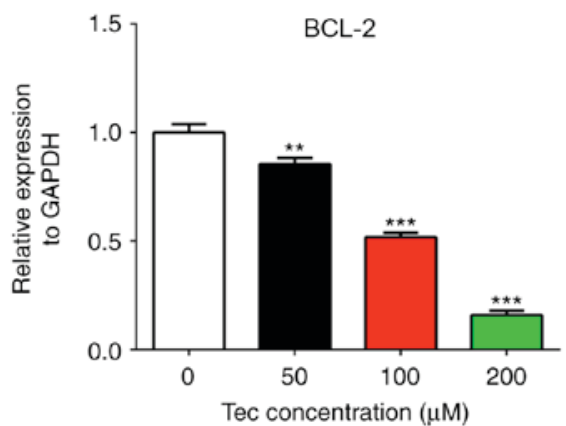

C

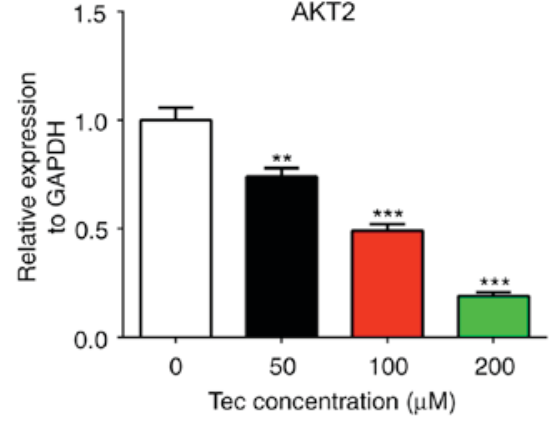

E

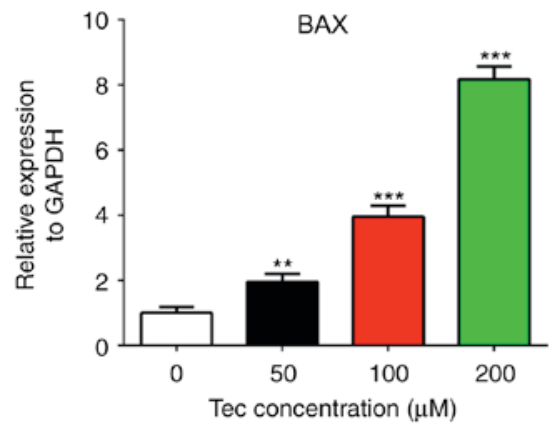

G

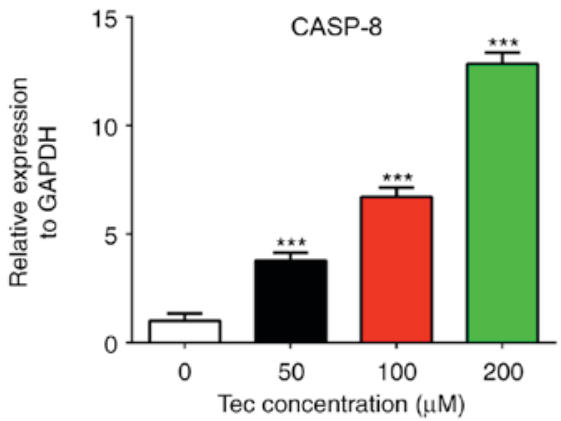

B

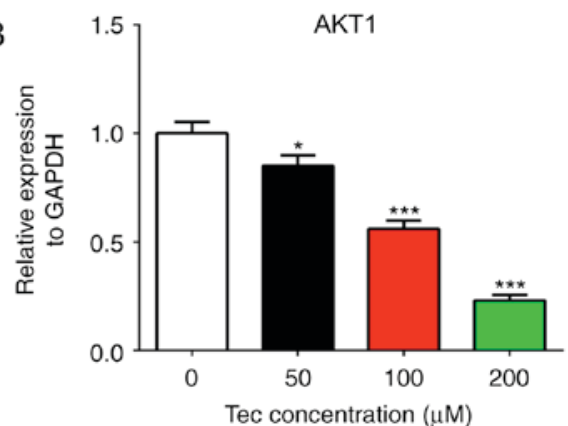

D

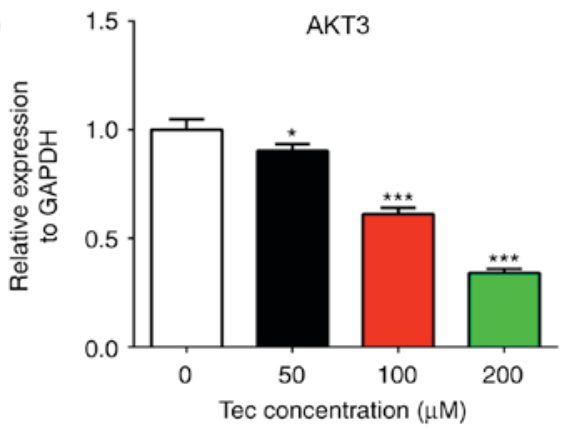

F

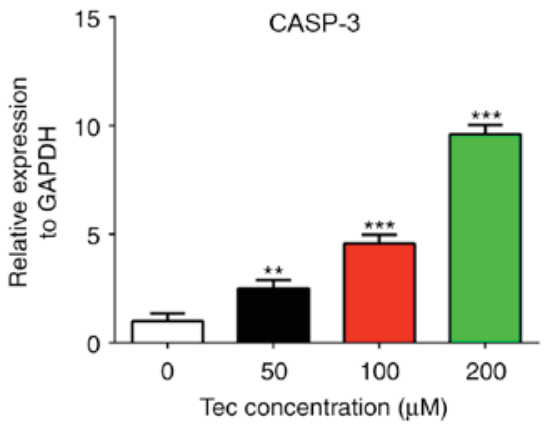

$\mathrm{H}$

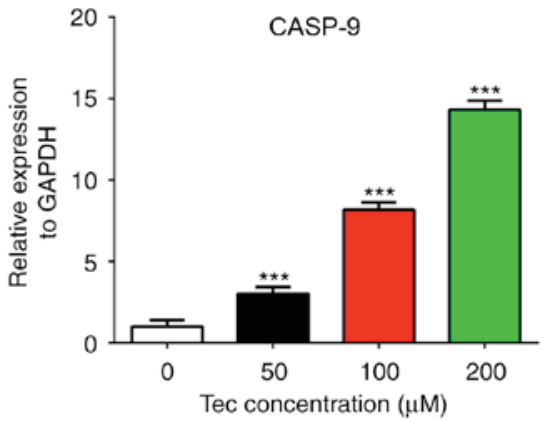

Figure 4. Apoptosis- and survival-related gene expression in MDA-MB-231 cells following Tec treatment. Reverse transcription-quantitative polymerase chain reaction was used to detect the mRNA expression levels of (A) BCL-2, (B) AKT1, (C) AKT2, (D) AKT3, (E) BAX, (F) CASP-3, (G) CASP-8 and (H) CASP-9 in Tec-treated MDA-MB-231 cells. Data are presented as the mean \pm standard deviation from at least three independent experiments; ${ }^{*} \mathrm{P}<0.05$, ${ }^{* *} \mathrm{P}<0.01$ and ${ }^{* * * *} \mathrm{P}<0.001$ vs. DMSO treated control $(0 \mu \mathrm{M})$. BAX, BCL-2-associated X; CASP, caspase; Tec, tectorigenin.

Tec treatment regulates the expression of apoptosis-related proteins and components of the MAPK signaling pathway. Western blotting was used to analyze protein expression levels of apoptosis-related proteins and components of the MAPK signaling pathway in MDA-MB-231 cells following different concentrations of Tec treatment. The results demonstrated that Tec treatment inhibited the protein expression of MAPK signaling proteins p-p38, p-JNK and p-ERK in (Fig. 5A and B). Tec treatment also suppressed the expression of BCL-2 and p-AKT in a dose-dependent manner (Fig. 5C and D). However, Tec treatment led to increased expression levels of BAX, cleaved PARP and cleaved CASP-3 in a dose-dependent manner (Fig. 5C-E). These data suggested that Tec treatment induced apoptosis of breast cancer cells through suppression of the MAPK pathway and by activation of CASP-3 dependent apoptosis.

\section{Discussion}

Although the current first-line therapies for breast cancer, which include surgery, radiotherapy and chemotherapy, have allowed for great achievements in clinical control, poor prognosis and serious side effects remain and must be addressed (19-24). Another primary problem of treatments 

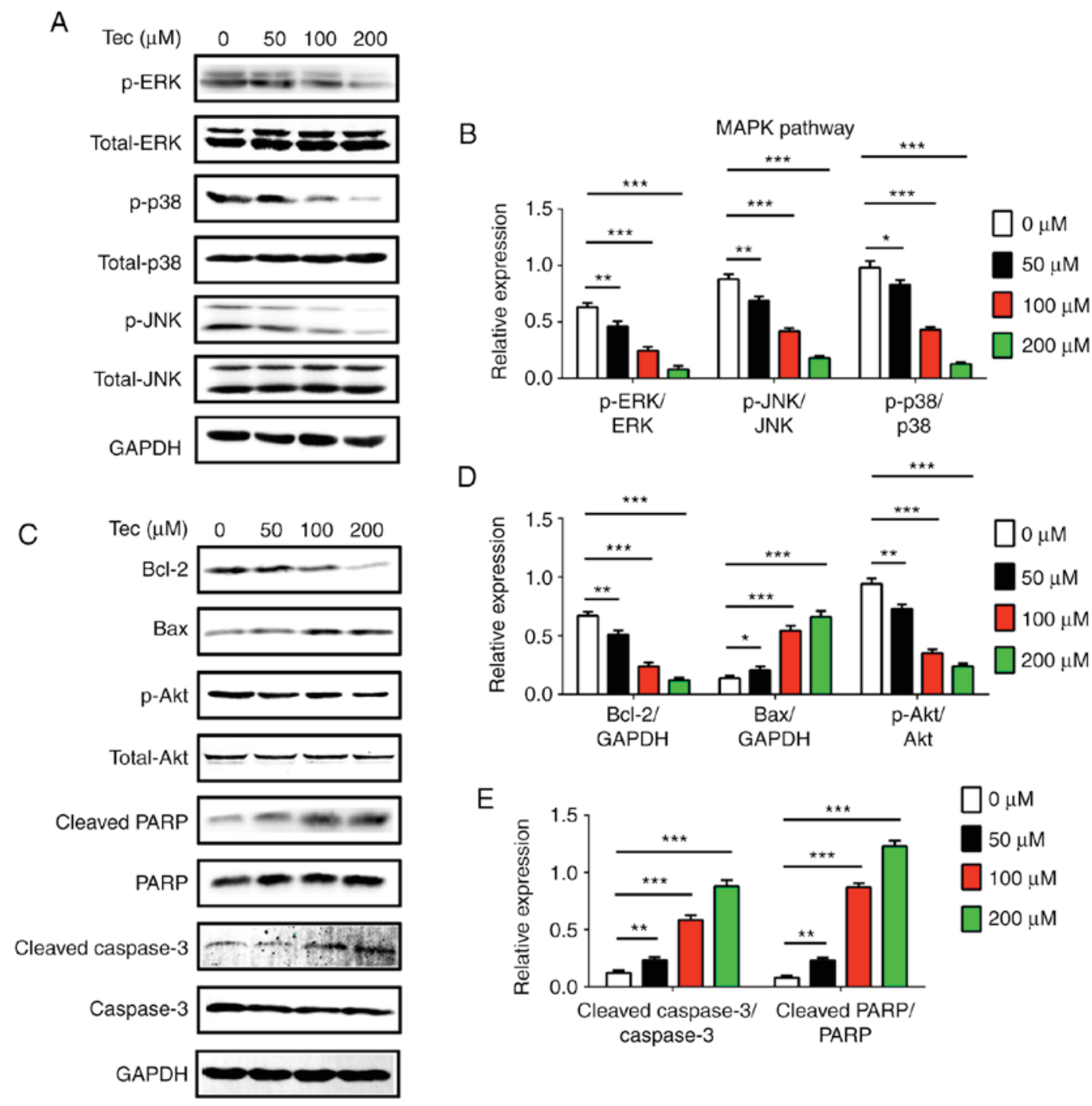

\section{E}

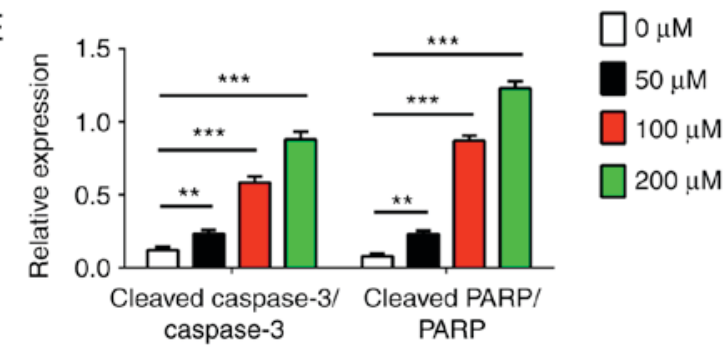

Figure 5. Western blotting of MAPK pathway components and apoptosis- and survival-related protein expression levels following Tec-induced apoptosis in MDA-MB-231 breast cancer cells. (A) Expression and (B) densitometric analysis of p-ERK/total-ERK, p-JNK/total-JNK and p-p38/p38 in MDA-MB-231 cells following Tec treatment. (C) Expression and (D and E) densitometric analysis of BCL-2, BAX, p-AKT/total-AKT, cleaved PARP/PARP and cleaved CASP-3/CASP-3 in MDA-MB-231 cells following Tec treatment. Results are expressed as the ratio to: GAPDH for BCL-2 and BAX, or total protein for p-AKT, p-ERK, p-JNK, p-p38, cleaved PARP and cleaved CASP-3. Data are presented as the mean \pm standard deviation from at least three independent experiments; ${ }^{*} \mathrm{P}<0.05,{ }^{* * *} \mathrm{P}<0.01$ and ${ }^{* * * *} \mathrm{P}<0.001$ vs. DMSO treated control $(0 \mu \mathrm{M})$. BAX, BCL-2-associated X; CASP, caspase; ERK, extracellular signal-regulated kinase; JNK, c-Jun N-terminal kinase; MAPK, mitogen-activated protein kinase; p, phosphorylated; PARP, poly [ADP-ribose] polymerase 1; Tec, tectorigenin.

for breast cancer is a high incidence of failure and relapse with drug resistance (4-6). Therefore, an increasing number of studies are exploring more efficient treatments for breast cancer, in which developing new drug treatments is a primary goal (1). TCMs may offer a primary source for the discovery of new anticancer drugs (25), and anticancer agents extracted from Chinese herbs have attracted further attention. For example, one recent study reported that Polyporus umbellatus including its ingredients ergosta-4,6,8 (14), 22-tetraen-3-one and polyporusterone A-G inhibited breast tumor cell proliferation and promoted apoptosis by downregulating AKT expression (26). Another recent study reported that emodin, a rhubarb-derived compound, inhibited breast cancer growth and metastasis (27).

Tec is one of the bioactive components that is purified from the Chinese herb Belamcanda chinensis that has been investigated in the treatment of certain cancers; a number of pharmacological effects have been identified $(28,29)$, which indicated that Tec may be an effective option for the treatment of breast cancer. The function and underlying mechanisms of Tec in breast cancer are not fully understood. To further investigate its potential clinical application, the present study examined the effects of Tec treatment on the proliferation, apoptosis, cell cycle, migration and invasion ability in human breast cancer cells in vitro.

The result demonstrated that up to Tec treatments did not influence the proliferation of hMSCs, whereas culturing MDA-MB-231 and MCF-7 cells with various concentrations inhibited their proliferation. Tec treatment also induced MDA-MB-231 cell apoptosis and G0/G1-phase arrest in a dose-dependent manner. The migration and invasion of MDA-MB-231 and MCF-7 cells were also inhibited by Tec in a dose-dependent manner probably through the suppression of MMP2 and MMP9 expression. These data indicated that 
Tec may be able to serve as an efficient chemotherapy drug for breast cancer treatment. However, a number of previous studies have reported that Tec stimulated the proliferation of MCF-7 and T-47D human breast cancer cells $(15,16)$. The present study suspected that the reason for this discrepancy is that a different number of cells used; for example, in the present study the CCK- 8 assay used 6,000 cells/well, whereas the previous studies used $1 \times 10^{4}$ cells/well. Another possible reason may be that the highest concentration of Tec in the previous studies was $100 \mu \mathrm{M}$ while the maximum concentration used in the present study was $200 \mu \mathrm{M}$, and the inhibition of the proliferation of tumor cells was not demonstrated in previous studies $(15,16)$; therefore, the inhibitory effects of Tec may not be obvious in these studies. The inhibitory effects of Tec in other tumors of epithelial origin, such as prostate cancer (30) and hepatocellular carcinoma (12), have been confirmed in other previous studies, and Tec treatment has now been confirmed to inhibit the proliferation of breast cancer cells by the present study.

The molecular mechanisms of Tec treatment on breast cancer cells were explored. Breast cancer cells often express continued active survival and signaling pathways, such as AKT and MAPK signaling, as well as gene mutation, rearrangements and chromosomal translocation in other signaling pathways (31-33). The survival-signaling pathway serves an important role in proliferation, tumorigenesis, anti-apoptosis and drug resistance $(34,35)$. The more constitutively active the survival signaling pathways are in breast cancer, the poorer is the prognosis (9). Apoptosis is an important mode of cell death during tumor chemotherapy. The caspase pathway is usually involved in the process of apoptosis, and CASP-3 is the main apoptogenic protein downstream of the mitochondrial apoptosis signaling pathways (17); it cleaves various key cellular substrates, therefore resulting in apoptosis (36). Cleavage of PARP is another defining characteristic of apoptosis, and serves a pivotal role in it (37). Heavy DNA damage usually results from apoptosis stimuli, which elicits a major increase in PARP activity, which rapidly depletes cellular levels of nicotinamide-adenine dinucleotide (NAD) ${ }^{+}$and ATP (38). Efforts to resynthesize $\mathrm{NAD}^{+}$increase ATP consumption, which leads to an energy crisis that results in cell apoptosis (39). Members of the BCL-2 protein family are key regulators of apoptosis, and the BCL-2/BAX ratio is a key determinant of apoptosis through the mitochondrial pathway (40). The present results indicated that the expression of BCL-2 was downregulated, whereas BAX expression was upregulated in breast cancer cells following treatment with Tec. These data also demonstrated that Tec treatment enhanced CASP-3, CASP-8, CASP-9 and PARP activity in a dose-dependent manner, which indicated that the mitochondrial apoptosis signaling pathway may be involved in breast cancer cell apoptosis induced by Tec. The MAPK and AKT signaling pathways are two main pathways that regulate cell proliferation in breast cancer (31-35). The present results demonstrated that both AKT and MAPK signal transduction pathways were suppressed simultaneously in Tec-treated breast cancer cells. It was hypothesized that Tec, by inhibiting the activation of AKT and MAPK pathways and promoting activation of the caspase family, may create a more effective response in antitumor therapy, as the inhibitor simultaneously targets three pathways in breast cancer cells. Tec may be more effective compared with specific inhibitors that have a single target for the treatment of breast cancer because drug resistance frequently emerges under single target treatments due to hyperactivation of alternative signaling pathways. In the present study, Tec treatment exhibited multi-targeted characteristics, and it is expected that resistance to Tec in breast cancer may occur rarely, response to Tec may be higher and the response duration may be longer.

Results from the present study have demonstrated the role of Tec in restricting proliferation, migration and invasion, and inducing apoptosis in human breast cancer cells. It was also revealed that Tec may indirectly or directly affect the vitality of AKT survival signaling, MAPK signaling and caspase-related apoptosis signaling, which are key regulators of cell survival and apoptosis during breast cancer treatment. However, further investigations should be conducted to better determine the in-depth molecular mechanisms controlling Tec-mediated effects on cell survival and apoptosis-related signaling pathways. In addition, animal experiments should be constructed to verify the therapeutic effect of Tec in vivo, and the present results should be verified by patient treatment trials.

In conclusion, the present study revealed the biological response of human breast cancer cells to a novel traditional Chinese herb Tec. It is suggested that Tec may induce apoptosis in breast cancer cells by downregulating the protein expression of p-AKT, BCL-2 and the MAPK pathway, and by upregulating the expression of cleaved CASP-3, cleaved PARP and BAX. In addition, Tec may be a potential therapeutic drug for human breast cancer. However, future work needs to be performed in additional cell lines to confirm these results for this molecule to be used in the clinic.

\section{Acknowledgements}

The present study was supported by The Health System 'Outstanding Young Talent' Cultivation Plan of Shanghai Jinshan District (grant no. JSYQ201620 to Xiangdong Kong), The Science and Technology Innovation Fund Projects of Shanghai Jinshan District (grant no. 2015-3-24 to Xiangdong Kong) and The Medical Subject Construction Fund Project of Shanghai Jinshan District (grant no. JSZK2015B06 to Ming Wu).

\section{References}

1. Kwak JH, Park JY, Lee D, Kwak JY, Park EH, Kim KH, Park HJ, Kim HY, Jang HJ, Ham J, et al: Inhibitory effects of ginseng sapogenins on the proliferation of triple negative breast cancer MDA-MB-231 cells. Bioorg Med Chem Lett 24: 5409-5412, 2014.

2. Wang P, Du X, Xiong M, Cui J, Yang Q, Wang W, Chen Y and Zhang T: Ginsenoside Rd attenuates breast cancer metastasis implicating derepressing microRNA-18a-regulated Smad2 expression. Sci Rep 6: 33709, 2016.

3. Jia Y, Wang $X$, Liu Q, Leung AW, Wang $P$ and $\mathrm{Xu}$ C: Sonodynamic action of hypocrellin B triggers cell apoptosis of breast cancer cells involving caspase pathway. Ultrasonics 73: 154-161, 2017.

4. Qiao H, Wang TY, Yan W, Qin A, Fan QM, Han XG, Wang YG and Tang TT: Synergistic suppression of human breast cancer cells by combination of plumbagin and zoledronic acid in vitro. Acta Pharmacol Sin 36: 1085-1098, 2015.

5. He J, Du L, Bao M, Zhang B, Qian H, Zhou Q and Cao Z: Oroxin A inhibits breast cancer cell growth by inducing robust endoplasmic reticulum stress and senescence. Anti-cancer Drugs 27: 204-215, 2016. 
6. Liedtke C, Mazouni C, Hess KR, André F, Tordai A, Mejia JA, Symmans WF, Gonzalez-Angulo AM, Hennessy B, Green M, et al: Response to neoadjuvant therapy and long-term survival in patients with triple-negative breast cancer. J Clin Oncol 26: 1275-1281, 2008.

7. Qu Z, Cui J, Harata-Lee Y, Aung TN, Feng Q, Raison JM, Kortschak RD and Adelson DL: Identification of candidate anti-cancer molecular mechanisms of compound kushen injection using functional genomics. Oncotarget 7 : 66003-66019, 2016.

8. Zhang Y, He L, Yue S, Huang Q, Zhang Y and Yang J: Characterization and evaluation of a self-microemulsifying drug delivery system containing tectorigenin, an isoflavone with low aqueous solubility and poor permeability. Drug Deliv 24 632-640, 2017.

9. Guo Y, Chen YH, Cheng ZH, Ou-Yang HN, Luo C and Guo ZL: Tectorigenin inhibits osteosarcoma cell migration through downregulation of matrix metalloproteinases in vitro. Anticancer Drugs 27: 540-546, 2016.

10. Yang YI, Lee KT, Park HJ, Kim TJ, Choi YS, Shih Ie M and Choi JH: Tectorigenin sensitizes paclitaxel-resistant human ovarian cancer cells through downregulation of the Akt and NFkB pathway. Carcinogenesis 33: 2488-2498, 2012.

11. Amin A, Mokhdomi TA, Bukhari S, Wani SH, Wafai AH, Lone GN, Qadri A and Qadri RA: Tectorigenin ablates the inflammation-induced epithelial-mesenchymal transition in a co-culture model of human lung carcinoma. Pharmacol Rep 67: 382-387, 2015

12. Jiang CP, Ding H, Shi DH, Wang YR, Li EG and Wu JH: Pro-apoptotic effects of tectorigenin on human hepatocellular carcinoma HepG2 cells. World J Gastroenterol 18: 1753-1764, 2012.

13. Lee KT, Sohn IC, Kim YK, Choi JH, Choi JW, Park HJ, Itoh Y and Miyamoto K: Tectorigenin, an isoflavone of Pueraria thunbergiana Benth., induces differentiation and apoptosis in human promyelocytic leukemia HL-60 cells. Biol Pharm Bull 24: 1117-1121, 2001.

14. Li QY, Chen L, Yan MM, Shi XJ and Zhong MK: Tectorigenin regulates adipogenic differentiation and adipocytokines secretion via PPAR $\gamma$ and $\mathrm{IKK} / \mathrm{NF}-\kappa \mathrm{B}$ signaling. Pharm Biol 53: 1567-1575, 2015.

15. Monthakantirat O, De-Eknamkul W, Umehara K, Yoshinaga Y Miyase T, Warashina T and Noguchi $\mathrm{H}$ : Phenolic constituents of the rhizomes of the Thai medicinal plant Belamcanda chinensis with proliferative activity for two breast cancer cell lines. J Nat Prod 68: 361-364, 2005.

16. Umehara K, Nemoto $K$, Matsushita A, Terada E, Monthakantirat O, De-Eknamkul W, Miyase T, Warashina T, Degawa $\mathrm{M}$ and Noguchi H: Flavonoids from the heartwood of the Thai medicinal plant Dalbergia parviflora and their effects on estrogenic-responsive human breast cancer cells. J Nat Prod 72: 2163-2168, 2009.

17. Han XG, Li Y, Mo HM, Li K, Lin D, Zhao CQ, Zhao J and Tang TT: TIMP3 regulates osteosarcoma cell migration, invasion and chemotherapeutic resistances. Tumour Biol 37: 8857-8867, 2016.

18. Livak KJ and Schmittgen TD: Analysis of relative gene expression data using real-time quantitative PCR and the 2(-Delta Delta C(T) method. Methods 25: 402-408, 2001.

19. Fang C, Wang FB, Li Y and Zeng XT: Down-regulation of miR-199b-5p is correlated with poor prognosis for breast cancer patients. Biomed Pharmacother 84: 1189-1193, 2016.

20. Chlebowski RT, Pan K and Col NF: Ovarian suppression in combination endocrine adjuvant therapy in premenopausal women with early breast cancer. Breast Cancer Res Treat 161 185-190, 2017.

21. Kong X, Li Z and Li X: GSTP1, GSTM1 and GSTT1 polymorphisms as predictors of response to chemotherapy in patients with breast cancer: A meta-analysis. Cancer Chemother Pharmacol 78: 1163-1173, 2016.
22. Sun S, Wang F, Dou H, Zhang L and Li J: Preventive effect of zoledronic acid on aromatase inhibitor-associated bone loss for postmenopausal breast cancer patients receiving adjuvant letrozole. Onco Targets Ther 9: 6029-6036, 2016.

23. Meng L, Xu Y, Xu C and Zhang W: Biomarker discovery to improve prediction of breast cancer survival: Using gene expression profiling, meta-analysis and tissue validation. Onco Targets Ther 9: 6177-6185, 2016

24. Fleisher B, Clarke C and Ait-Oudhia S: Current advances in biomarkers for targeted therapy in triple-negative breast cancer. Breast Cancer (Dove Med Press) 8: 183-197, 2016.

25. Wang X, Xia X, Leung AW, Xiang J, Jiang Y, Wang P, Xu J, $\mathrm{Yu} \mathrm{H}$, Bai D and Xu C: Ultrasound induces cellular destruction of nasopharyngeal carcinoma cells in the presence of curcumin. Ultrasonics 51: 165-170, 2011.

26. Tan XL, Guo L and Wang GH: Polyporus umbellatus inhibited tumor cell proliferation and promoted tumor cell apoptosis by down-regulating AKT in breast cancer. Biomed Pharmacother 83: 526-535, 2016.

27. Iwanowycz S, Wang J, Hodge J, Wang Y, Yu F and Fan D: Emodin inhibits breast cancer growth by blocking the tumor-promoting feedforward loop between cancer cells and macrophages. Mol Cancer Ther 15: 1931-1942, 2016.

28. Kapoor S: Tectorigenin and its inhibitory effects on tumor growth in systemic malignancies. Immunopharmacol Immunotoxicol 35: 533, 2013.

29. Ha le M, Que do TN, Huyen do TT, Long PQ and Dat NT: Toxicity, analgesic and anti-inflammatory activities of tectorigenin. Immunopharmacol Immunotoxicol 35: 336-340, 2013.

30. Thelen P, Scharf JG, Burfeind P, Hemmerlein B, Wuttke W, Spengler B, Christoffel V, Ringert RH and Seidlová-Wuttke D: Tectorigenin and other phytochemicals extracted from leopard lily Belamcanda chinensis affect new and established targets for therapies in prostate cancer. Carcinogenesis 26: 1360-1367, 2005.

31. Ho JY, Hsu RJ, Liu JM, Chen SC, Liao GS, Gao HW and Yu CP MicroRNA-382-5p aggravates breast cancer progression by regulating the RERG/Ras/ERK signaling axis. Oncotarget 8: 22443-22459, 2017.

32. Wang D, Wu P, Wang H, Zhu L, Zhao W and Lu Y: SIN1 promotes the proliferation and migration of breast cancer cells by Akt activation. Biosci Rep 36: e00424, 2016.

33. Wang H, Jia XH, Chen JR, Yi YJ, Wang JY, Li YJ and Xie SY: HOXB4 knockdown reverses multidrug resistance of human myelogenous leukemia K562/ADM cells by downregulating P-gp, MRP1 and BCRP expression via PI3K/Akt signaling pathway. Int J Oncol 49: 2529-2537, 2016.

34. Aghazadeh S and Yazdanparast R: Mycophenolic acid potentiates HER2-overexpressing SKBR3 breast cancer cell line to induce apoptosis: Involvement of AKT/FOXO1 and JAK2/STAT3 pathways. Apoptosis 21: 1302-1314, 2016.

35. Zhang Z, Liu L, Liu C, Cao S, Zhu Y and Mei Q: TIPE2 suppresses the tumorigenesis, growth and metastasis of breast cancer via inhibition of the AKT and p38 signaling pathways. Oncol Rep 36: 3311-3316, 2016.

36. Din TA, Seeni A, Yusoff MS, Shamsuddin S and Jaafar H: PF4-Induced apoptosis in breast cancer in vivo study: The role of the caspases family. Pathology 48 (Suppl 1): S122, 2016.

37. Lazebnik YA, Kaufmann SH, Desnoyers S, Poirier GG and Earnshaw WC: Cleavage of poly(ADP-ribose) polymerase by a proteinase with properties like ICE. Nature 371: 346-347, 1994.

38. Soldani C and Scovassi AI: Poly(ADP-ribose) polymerase-1 cleavage during apoptosis: An update. Apoptosis 7: 321-328, 2002.

39. Bhaskara VK, Panigrahi M, Challa S and Babu PP: Comparative status of activated ERK1/2 and PARP cleavage in human gliomas. Neuropathology 25: 48-53, 2005.

40. Sharifi S, Barar J, Hejazi MS and Samadi N: Roles of the Bcl-2/Bax ratio, caspase- 8 and 9 in resistance of breast cancer cells to paclitaxel. Asian Pac J Cancer Prev 15: 8617-8622, 2014. 